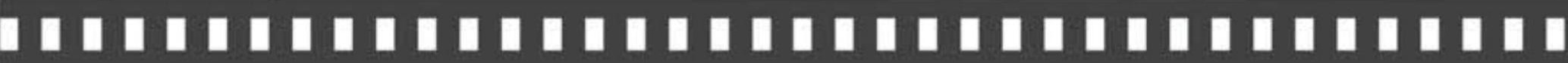

\author{
La fotografía en el cine de Pedro Almodóvar
}

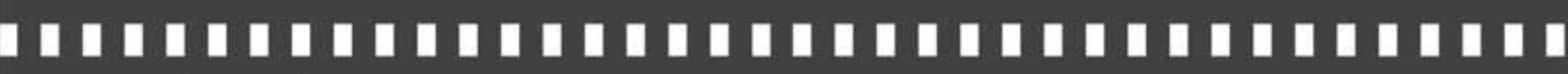

\author{
Nekane Parejo
}

Artigo recebido em: 02/11/2020

Artigo aprovado em: 02/12/2020

D0I 10.5433/1984-7939.2020v16n29p44 


\title{
La fotografía en el cine de Pedro Almodóvar
}

\author{
Photography in Pedro Almodóvar's Cinema
}

Nekane Parejo*

Resumen: Dentro del juego de intertextos al que Almodóvar nos tiene acostumbrados, esta investigación se centrará en cómo la imagen filmica aglutina en el metraje imágenes fotográficas. El propósito que se plantea será determinar qué fórmulas emplea este director, qué categorizaciones son susceptibles de configurarse a partir de las imágenes vinculadas a la fotografía que incorpora a sus películas y qué papel desempeñan dentro de ellas.

Palabras clave: Cine. Fotografía. Pedro Almodóvar. Intertextualidad.

Abstract: Within, these intertextual games that Almodóvar has familiarized us with, this research will focus on how the photographic images are brought together by the filmic image throughout the footage. In other words, the suggested purposes are to determine what formulas are used by this director, what categorizations can be configured from the images linked to the photography that he incorporates into his films and determine which role they play in the footage.

Keywords: Cinema. Photography. Pedro Almodóvar. Intertextuality.

* Profesora del Dpto. Comunicación Audiovisual y Publicidad, Fac. Ciencias de la Comunicación, Universidad de Málaga. Este artículo es el resultado de una investigación que se incluye en el Grupo de Investigación de la Junta de Andalucía SEJ-435, Contenidos Audiovisuales Avanzados. 


\section{Introducción: objetivos, metodología y marco teórico}

Metodológicamente partimos de la noción de Philippe Dubois sobre el campo de referencia que incluye tanto el "momento de la producción (relación con el referente y con el sujeto-operador: el gesto de la mirada sobre el objeto: el momento de la toma) como el de la recepción (relación con el sujeto-espectador: el gesto de la mirada sobre el signo: momento de la re-toma" (DUBOIS, 2002, p. 62). Esta reflexión nos lleva a considerar que el cineasta dispone de la capacidad para seleccionar dentro del campo de referencia al que alude este autor, aquellos segmentos visuales que considere adecuados para su película. Por tanto, el campo de referencia, al que accede el espectador, depende de los actos icónico-fotográficos que el director de cine reconstruye para su película. Esta enunciación conlleva la posibilidad de repensar sobre los procedimientos que este incluye en el metraje.

A partir de aquí este trabajo aborda, desde una perspectiva genérica, cómo la imagen fílmica acoge las imágenes fotográficas en la obra de Almodóvar ${ }^{1}$. Para afrontar esta cuestión se proponen tres objetivos específicos: el primero consiste en establecer cuáles son las fórmulas a las que atiende el cineasta para introducir imágenes estáticas en imágenes en movimiento, el segundo quiere responder a las categorizaciones que se pueden conformar a la vista de los modelos que se reiteran en su filmografía y, por último, precisar cuál es la función que acometen en el metraje. Se parte del supuesto de

1 Recuérdese que en la trayectoria de este autor conviven otras modalidades artísticas desde sus inicios. Para más información consúltese el artículo Pepi, Luci y Bom... Transgresión sexual y cultura popular (ARROYO, 2011). 
que la presencia de la fotografía en el cine de Almodóvar funciona como un objeto real a modo de ambientación, pero también se puede considerar como un elemento narrativo que permite avanzar el relato y excepcionalmente muestra cómo el cine deviene en foto.

Respecto al método, se ha considerado oportuno aplicar el análisis de contenido en su versión cualitativa. Esto implica iniciar la investigación con un universo cuya acotación temporal se corresponde con la totalidad de las producciones cinematográficas de Almodóvar, que van desde su primer largometraje en 1980, Pepi, Luci y Bom y otras chicas del montón, hasta la más reciente de 2019, Dolor y Gloria. Tras su revisión, y en función de una acotación temática basada en la presencia de fragmentos fotográficos, se establecerá la muestra. Finalmente, se fijarán las categorías a investigar mediante una clasificación de elaboración propia que parte de los estudios de Philippe Dubois, Raymond Bellour, Nekane Parejo y Antonio Pantoja.

En este sentido, y de manera general, han sido de utilidad las aportaciones de Philippe Dubois que parten de la noción de dispositivo. Es decir, cómo la fotografía a lo largo de su existencia ha sido presentada a través de diversos mecanismos que van desde los portarretratos, al álbum pasando por los periódicos, entre otros; y cómo el cine, como marco de la imagen fija, se ha convertido en un soporte más a tener en cuenta y cuyas peculiaridades deben ser objeto de estudio. De acuerdo con sus palabras en Cine y fotografía: "Cómo hacer hablar a/de una foto (en/por una película)" (DUBOIS, 2013, p. 140). Con anterioridad Dubois había establecido cuatro formas mediante las que a través del cine emerge la fotografía: cuando el realizador es un fotógrafo, cuando aborda una temática fotográfica, 
cuando cuenta con una forma fotográfica (congelados, ralentí...) y películas de efecto fotográfico (DUBOIS, 1987, p. 27-40).

Deforma más específica, se hatenido presente la categorización que Raymond Bellour propone en Entre Imágenes, que surge de un interrogante acorde con esta investigación: “¿Qué sucede cuando el espectador de cine encuentra la fotografía?" (BELLOUR, 2009, p. 77). Este autor reflexiona sobre diversas formas de inserción de la fotografía en el cine que van desde el objeto real con diversas funcionalidades, como expresar el transcurrir del tiempo o mostrar un descubrimiento, hasta el elemento primordial de la historia que se convierte en el soporte material de la película (BELLOUR, 2009, p. 77-82). En palabras de Domènec Font, retomando a este autor, "de la foto como presencia y pieza central del dispositivo del film a la foto-huella" (FONT, 2000, p. 22).

Por otra parte, Antonio Pantoja (2014) establece cuatro tipologías para determinar las vinculaciones entre la imagen fotográfica y las producciones cinematográficas. La primera incluye a los directores y creadores de imágenes que han trabajado en ambos formatos, la segunda a los directores de fotografía como responsables de la imagen retratada, la tercera la fotografía como referente visual y, la última, la fotografía como elemento narrativo.

Como decíamos, a partir de estas aportaciones hemos elaborado unas categorías que conformarán la estructura de este texto y que diferencian en un primer momento entre la fotografía como objeto real y lo que se denomina "lo fotográfico". En relación a este último término nos acogemos a la noción de Domènec Font (2000, p. 22) cuando manifiesta que se trata de un cine cuyas "imágenes, tiempos y relatos se trocean [...] permitiendo que algo se inmovilice 
en sus intersticios" o como lo expresa Nekane Parejo (2012, p. 73) "la esencia constitutiva del filme que se hace visible al espectador. Aquello que remite a la singularidad de la fotografía".

A su vez dentro de la fotografía como objeto real se han considerado dos bloques. Por un lado, las que pertenecen a la ambientación del metraje y por otro, las que funcionan como elemento narrativo, ya bien desde la imagen identificativa, la metáfora, o como detonante/inspiración de la narración. En cuanto al ámbito de lo fotográfico se ha subdividido en el congelado de imagen y la imagen fija recreada. Para abordar este concepto se ha seguido la clasificación de Parejo cuando se refiere a

[...] tres modalidades mediante las que lo fotográfico toma cuerpo en el filme: la detención de lo profílmico, el congelado de imagen y la inserción de fotografías [...] A las fórmulas anteriores se debe añadir, una cuarta en la que el fragmento puede construirse a través de la fotografía en tiempo secuencial, el time-lapse. (PAREJO, 2012, p. 75).

Sin embargo, al no encontrar muestras de la primera y la última en la filmografía de Almodóvar, se ha omitido su desarrollo en este trabajo.

\section{La fotografía como objeto real}

En esta tipología tendrán cabida aquellas copias que se han insertado en las películas de Almodóvar, pero que habitualmente cuentan con su propio contenedor. Es decir, se trata de fotografías enmarcadas, adheridas a una pared, insertas en una revista, un 
periódico, un álbum fotográfico... A su vez hemos dividido esta categoría en dos. La primera se corresponde con aquellas imágenes que actúan exclusivamente para ambientar un decorado. Mientras que en la segunda se abordan las que funcionan como elemento narrativo, lo que en la mayor parte de ocasiones se corresponde con el atrezo de actores. Para distinguirlas se puede decir que estos "son los objetos con los que juegan los actores (los que usan durante su interpretación)" (GUERRA, 1994, p. 180). Esta afirmación se puede extrapolar a aquellos objetos, en esta investigación fotografías, que sirven para el desarrollo de la trama cinematográfica. Sin embargo, "la ambientación engloba todo lo que forma parte del decorado" (REA, 1998, p. 178) pero carece de uso y no son piezas clave para el relato fílmico.

\section{La fotografía para la ambientación de decorados}

En este apartado es preciso subrayar la variedad de dispositivos en los que las encontramos. Los más habituales son las imágenes colocadas en una mesilla de noche o en la pared. Se observa una diferencia entre las primeras que se disponen en marcos que no pasan desapercibidos y las de la pared, ya bien a modo de póster, de recortes de revista o copias fotográficas, que cuentan con medios más rudimentarios. En algunas ocasiones se emplazan con unas simples chinchetas como las que sujetan las fotos de travestis de una revista bajo el título de "El travesti de la semana" en Pepi, Luci y Bom y otras chicas del montón (1980). En otras, se adhieren al espejo del baño como en Matador (1986). Otro mecanismo muy 
común son las fotos insertas en periódicos o revistas que ojean los personajes.

Por otro lado, se contemplan fotografías de gran tamaño que sirven de decorado a la escena y que integran a la protagonista totalmente en él como la playa idílica con palmeras en la que se inserta Leo (Marisa Paredes) cuando entra en un bar; que además sirve de contrapunto a la tormenta de la que se cobija en La Flor de mi secreto (1995). En esta línea, pero con un formato aún mayor, encontramos una imagen publicitaria de la obra teatral Un tranvía llamado deseo con la cara de Huma Rojo (Marisa Paredes) que sirve de decorado para la espera de Manuela (Cecilia Roth) a su hijo Esteban (Eloy Azorín) en Todo sobre mi madre (1999). La cámara cinematográfica se deleita con diversos planos de está saturada imagen que cuenta con gran presencia de grano. Tras mostrarla entera, será Manuela la que entre en plano y a partir de ahí, la distancia narrativa se aproxima y enmarca distintas partes del rostro de Huma Rojo hasta llegar a la abstracción puntillista en un plano medio corto de Manuela.

Aunque con menos frecuencia, también se observan algunos enmarcados peculiares como las copias que forman parte de series. Es el caso del collage fotográfico, que conforma el cabecero de Ramón (Álex Casanovas) en Kika (1993) o el enmarcado en hileras de Carne trémula (1997). En el primero confluyen indiscriminadamente imágenes religiosas con collages publicitarios y algunas tomas de desnudos. En el segundo se observan cuatro hileras en vertical y una en horizontal en las que se han introducido copias a modo de fotogramas secuenciales de los encuentros de baloncesto de David (Javier Bardem).

Mención a parte, requieren los álbumes que elabora la madre del 
juez Domínguez (Miguel Bosé) interpretada por Mayrata O'Wisiedo en Tacones lejanos (1991). Se trata de álbumes monotemáticos, con portadas confeccionadas artesanalmente (incluso con encajes) en los que esta recorta y pega las fotografías de personajes famosos que encuentra en los periódicos. Precisamente este será uno de los contenidos más recurrentes de estas imágenes. En concreto, en esta película se distinguen, entre otros, uno de su protagonista, la famosa intérprete Becky del Páramo (Marisa Paredes) y otro de Brigitte Bardot.

En cuanto a los contenidos de estas fotografías destacan, como decíamos, las tomas (homenaje) de reconocidas actrices internacionales (en palabras de la madre superiora (Julieta Serrano) del convento de Entre tinieblas (1983) "algunas de las grandes pecadoras de este siglo") como Grace Kelly, Jean Dean, Marlene Dietrich, Brigitte Bardot, Elizabeth Taylor, Ava Gardner, Bette Davies, Marilyn Monroe, etc. En su mayoría mujeres y grandes divas de la escena hollywoodiense de los años 40 y 50 :

Desde el debut en Pepi, Lucy, Bom y otras chicas del montón, la presencia de grandes estrellas de Hollywood ha sido un referente. El recurso se repite en, prácticamente, todas sus películas, alcanzando el paroxismo en los domicilios de los protagonistas de La ley del deseo y Kika; es allí donde se idolatra a Elisabeth Taylor y Marilyn Monroe mediante fotografías que comparten altar con otras referencias culturales y religiosas". (PERALES, 2008, p. 284).

Otro contenido que se reitera son las fotos de familia. No nos referimos a aquellas que sirven para presentar o identificar a un personaje (a las que se aludirá en el epígrafe sobre la fotografía como 
elemento narrativo) sino a aquellas que decoran y que, en ocasiones, funcionan como punto de arranque de algún movimiento de cámara. Por ejemplo, a partir de la foto de Kika comienza un zoom out que permite verla leyendo una carta (paradójicamente ambas visten de rojo). En Todo sobre mi madre se asiste al inicio de una panorámica que muestra varias instantáneas para acabar en Manuela dormida. Dentro de las fotografías de ambientación de carácter familiar es necesario mencionar una tipología que se reitera, las de primera comunión. En ¿Qué he hecho yo para merecer esto! (1984) vemos una imagen de estas características sin enmarcar en una pared tras el rostro de Gloria (Carmen Maura). Del mismo modo en La mala educación (2004), y mientras la madre y la abuela de Juan / Ángel (Gael García Bernal) e Ignacio (Francisco Boira) hablan por teléfono, sobre la pared y enmarcadas se aprecian diversas fotos de familia (bodas... y por supuesto, una niña de comunión). Si bien estas instantáneas solo adornan las estancias, en ocasiones desarrollan una funcionalidad más evidente como veremos en el siguiente epígrafe.

Por otra parte, es necesario referir que en las primeras películas de Almodóvar se localizan fotos relacionadas con el desnudo. Ya mencionamos las de travestis en Pepi, Lucy y Bom y otras chicas del montón. En esta misma producción el policía (Félix Rotaeta) hojea una revista con imágenes de chicas desnudas. En la habitación de Sádec (Antonio Banderas) en Laberinto de pasiones (1982) la cámara se hace eco de varios desnudos fotográficos de gais pegados a la pared, cuando este mantiene su primera relación sexual con Riza (Imanol Arias).

Otro aspecto que es necesario subrayar es la evidente intencionalidad y motivación por parte del cineasta a la hora de 
seleccionar las imágenes fijas que aparecerán en el metraje: "Muchas fotos que salen en mi cine tienen además gran valor sentimental para mí, como la de Pina Bausch en la cabecera de la cama de Leonor Watling en Hable con ella. En general, muestro retratos que tienen que ver conmigo" (BELINCHÓN, 2018). Almodóvar explicita en una escena anterior cómo Benigno (Javier Cámara) le cuenta a Alicia (Leonor Watling) que la tarde anterior había comprado la fotografía y conseguido el autógrafo de la famosa bailarina. Poco después, la veremos enmarcada y como parte de la ambientación.

Por último, se debe señalar que el valor sentimental al que alude Almodóvar no se limita a insertar fotografías de ambientación en las que aparecen famosos, sino que también introduce imágenes fijas de conocidos fotógrafos. Es el caso de los collages de Dis Berlín que se localizan en Kika o las de la serie Peluquería de Ouka Leele que adornan las paredes de la vivienda de la madre de Angustias (Concha Grégori) en Laberinto de Pasiones.

\section{La fotografía como elemento narrativo}

André Bazin propone la siguiente diferenciación entre fotografía y cine: "la fotografía es una técnica incompleta en la medida en que la instantaneidad le obliga a no captar el tiempo que detiene. El cine realiza la extraña paradoja de amoldarse al tiempo del objeto y de conseguir además la huella de su duración" (BAZIN, 1990, p. 173). Desde este planteamiento, ese objeto instantáneo, que es la fotografía, mediante la duración que el cine le confiere, puede adquirir una nueva capacidad como elemento narrativo. Esta 
capacidad, en el objeto de esta investigación, se presenta de diferentes formas que se desarrollan a continuación: la fotografía identificativa en su triple versión como elemento del pasado que entronca con el recuerdo, artífice de un descubrimiento que permite avanzar la narración y como medio de presentación de algún personaje, la foto metafórica y excepcionalmente, como detonante de la narración, pero con matices que se explicitarán más adelante.

A) Identificativa: pasado, presentación y descubrimiento

Las copias fotográficas identificativas, tal y como decíamos, cuentan con tres utilidades principalmente: mostrar el pasado, presentación de personajes al espectador y consumar descubrimientos. En cualquier caso, son usos que permiten a este avanzar en la construcción de la historia. En el apartado anterior, aunque de forma transversal, ya hemos dado cuenta de la presencia del pasado en las imágenes de ambientación. Nos referimos ahora a aquellas imágenes que se sitúan en un tiempo anterior, y que sirven para que emerjan recuerdos o para avivar la memoria de los protagonistas.

En este sentido, las más obvias son las que en La ley del deseo (1987) Tina (Carmen Maura) le enseña a su hermano Pablo (Eusebio Poncela) en estado amnésico tras un accidente. Inicialmente le muestra dos fotos enmarcadas que se corresponden con una de ella, más próxima a la actualidad, y otra en la que están el director de cine y Tina de bebé. Como el olvido persiste le dice, "Tu amnesia me deja sin pasado" y coge otras instantáneas (ahora sin enmarcar). En la primera se ve a dos chicos. Tina le explica que son ellos dos y entonces Pablo se percata de que su hermana era un chico. Por tanto, esta imagen funcionará también como catalizador de un descubrimiento. 
Pasado y presente se funden mediante nuevas imágenes de primera comunión como en La mala educación donde el padre Manolo (Daniel Giménez Cacho) tras la visita del hermano de Ignacio recupera la imagen de Ignacio niño (Ignacio Pérez) guardada en un cajón. O cómo en ¡Átame! (1989) donde sobre la mesilla de noche durante el secuestro de Marina (Victoria Abril) se localiza una imagen en la que aparecen dos mujeres y delante una niña vestida de comunión. Sin duda esta imagen refuerza la idea de familia tradicional que pretende lograr Ricky (Antonio Banderas) con Marina. Por último, el atípico retrato de comunión de Elena (Francesca Neri) en un balcón con un fondo montañoso en Carne trémula. Aquí, ante la imposibilidad de Víctor (Liberto Rabal) de mantener una conversación con ella, este dirige sus palabras a la citada fotografía. De esta manera, la imagen remarca la oposición entre la niña y la actual Elena. Pedro Poyato considera que de este modo se establece un nexo entre sexo y Cristo:

Víctor fija su atención en una fotografía de Elena a la que se dirige en estos términos: "Te conozco desde hace una semana. Echamos un polvo de puta madre. Para mi era la primera vez ¿Tú sabes lo que es eso?” [...] Dado que las palabras de Víctor como la fotografía de Elena aluden a una primera vez, es clara la vinculación que el filme establece aquí entre el sexo y Cristo. (POYATO, 2012a, p. 131-132).

Raymond Bellour se cuestiona sobre la utilidad de este tipo de fotografías, que según sus palabras "hacen de bisagra entre dos partes del relato; expresan el paso del tiempo" (BELLOUR, 2009, p. 78). Así lo hemos visto en las escenas anteriores y lo volvemos a 
encontrar en Carne trémula donde al principio del metraje se inserta un falso NODO en el que se escuchan los disparos de las cámaras fotográficas (e incluso se ve a un reportero de espaldas) que retratan a Isabel (Penélope Cruz) en el hospital con su bebé en brazos, Víctor. Pedro Poyato (2012a, p. 127) describe que las imágenes "muestran al alcalde de Madrid visitando a Isabel y a su bebé en el hospital para regalarle la primera canastilla y nombrar al niño hijo adoptivo de la ciudad. Monjas y enfermeras rodean al ilustre visitante, haciendo notar su presencia mediante miradas cómplices a la cámara". En este punto se debe matizar que estas miradas que parecen dirigidas a la cámara cinematográfica, más tarde el metraje dará cuenta de la copia fotográfica inserta en un diario. Y es a través de esta instantánea donde la fotografía aúna dos lapsos temporales, el de la infancia de Víctor y el actual, cuando en la cárcel recibe una carta de su madre enferma terminal de cáncer y una segunda fotografía de estudio en tonalidades sepia en la que se encuentran ambos.

En cuanto a las fotografías que propician un descubrimiento que permite avanzar la narración están relacionadas con dos posibilidades: el descubrimiento de la identidad de alguno de los personajes o con sus relaciones afectivas o de parentesco. En el primer caso, destaca el momento en el que la madre de Ignacio y Juan/Ángel le descubre a Enrique (Fele Martínez) que este último tiene un hermano mientras contemplan las imágenes colgadas en la pared de ambos en La mala educación. En esta línea, en Laberinto de pasiones, a través de una foto de Sádec vestido de mujer, Riza averigua que este es tiraní o mediante las explicaciones de un miembro del grupo musical Ellos ante cuatro instantáneas, que Sexilia (Cecilia Roth) es ninfómana. También mediante una foto en Tacones Lejanos 
Paula (Cristina Marcos) se entera que su novio era confidente de la policía y ha muerto. En esta misma película, pero más asociada a las relaciones afectivas, será una foto de prensa la que delate el vínculo entre Becky y Manuel (Feódor Atkine). Además, servirá para que el juez Domínguez pueda ir esclareciendo su muerte. Sin duda, las fotografías se convierten en un canal muy fluido que destapan infidelidades y paternidades ocultas como en Carne trémula donde Sancho (José Sancho) descubre que su mujer se acuesta con Víctor a través de unas imágenes robadas que le muestra David o en Mujeres al borde de un ataque de nervios (1988) cuando Carlos (Antonio Banderas) ve en una foto a su padre con Pepa (Carmen Maura) y deduce que es su amante.

Mención a parte requiere Los abrazos rotos (2009) donde se produce un doble descubrimiento cuando el ayudante de Harry (Lluís Homar) (Harry Caine es el nombre que adopta el director de cine Mateo Blanco cuando se queda ciego), Diego (Tamar Novas), a instancias de este busca en un cajón unas fotografías que le revelen la identidad de Ray X (Rubén Ochandiano) (qué acaba de visitarle para proponerle una producción). Entre las instantáneas que encuentra Diego destacan dos: una de Ray X con Mateo Blanco (cuya identidad es averiguada por las descripciones de Harry) y otra en la que aparecen la madre de Diego, Judit (Blanca Portillo) y el cineasta en un ambiente playero. Poyato considera que "no resulta difícil adivinar ahora que esas fotos que interrogan a Diego estén vinculadas a sus orígenes" (POYATO, 2012b, p. 10). Al final de la película su madre le confesará que Harry es su padre.

Por último, en Entre tinieblas la madre superiora recibe una carta de África con una foto en la que aparece un chico al que 
abraza un mono, en clara alusión a Tarzán. Al final de la película la marquesa (Mari Carrillo), que subvencionaba el convento, recupera la carta y descubre que el muchacho de la foto es su nieto. En este sentido, Francisco Perales incide en las referencias al cine clásico por parte del Almodóvar, "una fotografía del nieto de la marquesa, fruto de una pasión pecaminosa entre su hija y un indígena, es la excusa perfecta para incluir la figura de Tarzán" (PERALES, 2008, p. 284).

En cuanto a la presentación de personajes, se trata de imágenes que se sitúan al comienzo de los metrajes y que adoptan diferentes fórmulas. Las más habituales remiten a que la cámara se centre en el marco de una fotografía mientras el diálogo la describe. En la película anterior se presenta a la hija de la marquesa con la madre superiora a su izquierda y sor Rata del Callejón (Chus Lampreave) a la derecha (además de las palabras de la marquesa, sus labios rojos marcados sobre la figura del centro señalan con cuál de las tres monjas tiene parentesco). En esta misma línea, al comienzo de Matador Ángel (Antonio Banderas) contempla unas fotografías que Diego (Nacho Martínez) tiene en su mesilla mientras le pregunta sobre ellas. Esta escena no solo sirve para presentar a la novia del torero, Eva (Eva Cobo), sino para conocer su profesión y qué es vecina de Ángel. Además, la primera fotografía por la que se interesa este, una de Ava Gadner, a quien no conoce, funciona para marcar su perfil (no va al cine, su familia es del Opus, reza y hace gimnasia).

Otra modalidad es que la imagen del personaje al que se presenta se encuentre en un periódico como la del empresario Ernesto Martel (José Luis Gómez) con motivo de su muerte el 4 de abril de 2008 en El País que se inserta en Los abrazos rotos o la 
que se reproduce en la portada de este mismo diario del doctor de la Peña (Fernando Vivanco) y padre de Sexi informando sobre el hecho de que logra por primera vez la reproducción de periquitos en Laberinto de pasiones. De acuerdo con Sánchez Noriega en su escritorio "hay fotografías de animales en lugar de retratos de sus hijos o su esposa, lo que refleja la paranoia de este investigador" (SÁNCHEZ NORIEGA, 2017, p. 221).

\section{B) Fotografía metafórica}

Como continuación a lo expresado en el epígrafe anterior es preciso señalar que en varias de las producciones de Almodóvar se reitera una misma estructura que muestra en un primer momento una fotografía de una pareja sonriente (momento de la presentación) y posteriormente vemos cómo esa imagen es usada por algún miembro de esa pareja (normalmente la mujer) para evidenciar su ruptura. La flor de mi secreto comienza con una panorámica horizontal que muestra varias fotografías enmarcadas de Leo y Paco (Imanol Arias) y entre ellas destaca una en la que se están besando. Ante las evasivas de este, Leo estampa la imagen contra el suelo y la estructura de bolas que conforma el marco rebota mientras la cámara se centra en la rotura de la moldura que se convierte en una metáfora de la ruptura de su matrimonio. Una versión del planteamiento anterior se encuentra en Mujeres al borde de un ataque de nervios, que también arranca con una foto en la mesilla, en esta ocasión, de una pareja de amantes, Pepa e Iván (Fernando Guillén). Se trata de una imagen a la que acompaña una dedicatoria: "Te amo, te quiero, te deseo, Iván" y que más tarde, cuando la mujer de Iván, Lucía (Julieta Serrano), la descubre también la arrojará al suelo. En este caso deseando su ruptura, que, aunque ya se ha producido, esta lo desconoce. También, 
pero esta vez desde la ventana, será lanzada una bolsa con algunos objetos, que caerán sobre la cabina telefónica en la que se encuentra Pepa intentado hablar con Iván. Entre estos un portarretratos con una foto de este con su hijo Carlos, en cuya parte inferior está escrito: "De tu padre que no te merece, Iván". De este modo, esta se entera de que su amante tiene un hijo. Por tanto, nuevamente vemos que se combinan la instantánea que descubre un parentesco y la imagen (arrojada) como símbolo del final de una relación. En Kika la ruptura viene de la mano de la supuesta nota de suicidio de Rafaela (Charo López) junto a la imagen de ella y su marido, Nicholas (Peter Coyote) abrazados y sonrientes. Posteriormente, la película terminará, cuando Nicholas le lanza una foto de su mujer, a la que asesinó, a Kika; ahora como arma defensiva.

Las funcionalidades de las fotografías de las producciones de Almodóvar son diversas y de acuerdo con Dubois consideramos que encuentran su justificación en que "una foto es un objeto concreto, material, "palpable", se puede tocar, coger, robar, coleccionar, romper, abrazar, quemar, es, en este sentido, un verdadero objetofetiche y ello se debe a que la propia imagen (representación) es materialmente indisoluble de su soporte físico" (DUBOIS, 2000, p. 133).

Otra acción, la que más se repite, es la de rasgar una fotografía. En relación a este tema Sánchez Noriega (2017, p. 2019) se refiere a "una especialización con la foto rota [...] para ritualizar un desamor o, por el contrario, fragmentos que hay que recomponer como sortilegio para rescatar un pasado de amores y pasiones". Y así, encontramos a Pepa en Mujeres al borde un ataque de nervios seccionando una foto con Iván o a Yolanda (Cristina Sánchez Pascual) cortando con unas 
tijeras una imagen en la que aparece con su novio (con el que acaba de romper) para firmar un autógrafo a la madre superiora y a sor Estiércol (Marisa Paredes) en Entre tinieblas. A veces, no se trata de evidenciar un desamor, sino todo lo contrario. En La Ley del deseo Pablo rompe las fotos de su infancia con su hermana (que ahora es transexual) para demostrarle su afecto.

En ocasiones, como manifiesta Sánchez Noriega, Almodóvar presenta la fotografía fragmentada para que el metraje se encargue de su reconstrucción. Por tanto, estamos ante una estructura inversa a la contemplada hasta el momento. Antes de continuar, se debe recordar que al inicio de este trabajo indicábamos la capacidad del cineasta para decidir incluir en su película unos actos icónico-fotográficos $\mathrm{u}$ otros dentro del campo de referencia establecido por Dubois. En este momento estamos en condiciones de afirmar que se ha ratificado lo expuesto, pero que además el director de cine, puede optar por romper el marco que a priori el fotógrafo seleccionó. Este mismo autor cuando se refiere al corte temporal señala que "El fotógrafo no puede llenar progresivamente el marco vacío. Su gesto consiste más bien en sustraer de un golpe todo un espacio pleno" (DUBOIS, 2002, p. 158). Y precisamente ese espacio puede contener a dos personas, pero Almodóvar opta deliberadamente por mostrar solo a una en las copias fotográficas cuando en el metraje una de las mitades se omite.

En Todo sobre mi madre Manuela le enseña a su hijo Esteban una fotografía de cuando actuaba en un teatro amateur. Llama la atención que a la imagen le falta la mitad. El monólogo de Esteban evidencia que no se trata de un caso único: "Esta mañana he revuelto en sus cajones y he descubierto un fajo de fotos. A todas les faltaba la mitad". De acuerdo con Mark Allison esta escena plantea el tipo 
de separación y la ausencia de la figura paterna:

Esteban acaricia el borde desgarrado, su misma textura indicando una ruptura nada limpia. El primer plano del punto de vista de Esteban comunica visualmente lo que escribe a continuación en su cuaderno: esta fotografía simboliza la mitad de Esteban que siempre siente que le falta: su padre (ALLISON, 2005, p. 153).

Posteriormente, en esta misma película, con la misma composición triangular que veíamos en Entre tinieblas, se aprecia a tres amigas Agrado (Antonia San Juan), Manuela y Lola (Tony Cantó). Lo que pudiera parecer una simple foto de presentación, con connotaciones que evidencian la nostalgia de un pasado mediante la cámara cinematográfica deviene en un plano más próximo que enmarca solo a Lola y Manuela en la instantánea. De este modo, se reconstruye la pareja de una imagen rota y sirve de indicio para el espectador de lo que más tarde el cineasta revelará, que tuvieron una relación de la que es hijo Esteban.

En Los abrazos rotos se localiza otra muestra de este proceder basada en la reconstrucción de una imagen. En un accidente de tráfico Lena (Penélope Cruz) muere y Mateo se ha quedado ciego. Judit va al bungalow de la playa de Famara, donde estos pasaron los últimos días, y allí encuentra una bolsa en la papelera que contiene los fragmentos de las fotografías que la pareja se hizo durante su estancia en la isla. Posteriormente, el metraje da cuenta de cómo Diego recompone una de las instantáneas. Se trata de un autorretrato, de ambos sonrientes y abrazados en un sofá, del que el metraje muestra su preparación y el acto fotográfico; pero donde deliberadamente se 
omite el congelado de la imagen que es sustituido por una pantalla en blanco, en claro simbolismo de una relación malograda que deviene en una fotografía rota que finalmente se recompone en una imagenpuzle. Una imagen-puzle que remite a "un abrazo resquebrajado, (donde) su memoria remite a un abrazo segado por la muerte de la mujer; un abrazo, en definitiva, roto como refleja en título del filme" (POYATO, 2015, p. 81).

En ¿Qué he hecho yo para merecer esto! se aúnan las posibilidades expuestas y la película muestra el momento en el que se secciona la fotografía y la intención de recomponerla. Además, se materializa el hecho de que uno de los personajes canaliza su rabia mediante la rotura, a la par que otro muestra su amor a través de la reconstrucción. Así, Juani (Kiti Mánver) rompe una foto de su marido en presencia de su hija Vanesa (Sonia Anabela Holimann), que adora a su padre, y que inmediatamente trata de ensamblar los pedazos.

C) Detonante de la narración / de la inspiración

Una o varias fotografías en ocasiones se convierten en el detonante de la narración fílmica. Lo habitual es que estas imágenes se sitúen al comienzo de esta y el metraje revele el acto fotográfico y elabore su reconstrucción. Lo vemos en producciones como Flag of Ours Fathers / Banderas de nuestros padres (Clint Eastwood, 2006), en Amélie (Pierre Jeune, 2001) o Ulysse (Agnès Varda, 1983), entre otras. Aunque por distintos motivos estamos ante fotografías imprescindibles para el discurrir de la historia. E indispensable es la foto realizada por Pedro Almodóvar en unas vacaciones en 1999 que de acuerdo con Broullón (2011, p. 134) "dio lugar a la oportunidad de escribir el guion". En esta fotografía, desde una angulación en 
picado, muestra a una pareja (de tamaño reducido) abrazándose, ajena al fotógrafo. Se trata de una toma cuyo acto fotográfico e imagen detenida recreará la cámara de cine en Los abrazos rotos, captada por el cineasta Mateo Blanco en su viaje con Lena a Lanzarote. Sin embargo, a diferencia de las películas mencionadas donde la imagen está presente desde el principio y la historia gira en torno a ellas, en Los abrazos rotos la contemplamos casi al final. En las otras producciones, por ejemplo, en Banderas de nuestros padres, recuérdese que la conocida fotografía de Joe Roshental, es encontrada por el hijo de Jhon Bradley, uno de los seis soldados de Iwo Jima a los pocos minutos de iniciarse el metraje; al igual que la foto que localiza en una caja Amélie, que es el detonante para que se plantee que si su propietario se conmueve se dedicará a ayudar a los demás. En el caso de Ulysse la estructura difiere, ya que la foto también se presenta al principio, pero para posteriormente (28 años más tarde) optar por recrear la misma imagen, después de investigar la identidad de los protagonistas.

Almodóvar no se interesa por indagar sobre quiénes son los protagonistas de la imagen (en los cuales cuando hace la foto no repara $)^{2}$, pero esta le sirve para construir una historia de ficción. Podemos convenir que para Almodóvar esta fotografía funciona como detonante para la inspiración, mientras en las producciones mencionadas se trata del detonante para la investigación.

2 Por este motivo numerosos investigadores como Ana Melendo (2012) o Pedro Poyato (2012b) la han comparado con la fotografía que da lugar a sucesivas ampliaciones en Blow up (Michelangelo Antonioni, 1966). 


\section{Lo fotográfico en el cine}

Desde una perspectiva histórica las relaciones entre fotografía y cine remiten a los orígenes de este último, en concreto a finales del siglo XIX. En ese momento se genera la necesidad de analizar los objetos en movimiento y plasmarlos. Y es ahí, donde coinciden dos prácticas, que a priori pudieran parecer semejantes, la cronofotografía y la cinematografía ${ }^{3}$. Dos prácticas similares, pero también diferentes, ya que mientras la cronofotografía descompone el movimiento, el cine lo reestablece a partir de la proyección de imágenes fijas ${ }^{4}$. En este sentido, Philippe Dubois se refiere al hecho de que estamos ante dos mecanismos que conforman las dos caras de una misma moneda y que se complementan. Es decir, los avances en cronofotografía conllevan el descubrimiento del cine, aunque se trate:

Por un lado, de fabricar una representación lo más "realista" posible, dado que reproduce fielmente el movimiento de lo real (aunque sea mediante una ilusión óptica) ${ }^{5}$ y, por otro alcanzar una representación "desrealizadora" que va más allá de la visión "normal" y nos permite ver aquello que el ojo nunca ha visto. (DUBOIS, 2000, p. 137).

\section{Si traemos aquí a colación esta incipiente relación se debe}

3 Aunque ya desde su etimología griega se observan diferencias: crono remite a tiempo y kinema al movimiento.

4 Este propósito no es exclusivo de la cinematografía, ya que los científicos también se sintieron atraídos por mecanismos que les permitieran transcribir el movimiento desde sus series de imágenes estáticas, pero con otra finalidad. En concreto, se debe señalar que: "nunca se trata de promover una ilusión de continuidad (ni siquiera en el zoopraxiscopio de Muybridge, que reconstruía los desplazamientos de forma fluida pero solo para comprobar que su método descompositivo era exacto)" (OUBIÑA, 2009, p. 51).

5 En este sentido, Moholy-Nagy (2005, p. 43) afirma que: "La fuerza del cine reside en su capacidad de crear la impresión de una realidad espacio-temporal coherente, incluso cuando esta realidad solo ha podido existir anteriormente de forma dispersa y fragmentada". 
a que ya desde sus orígenes el cine prescribe la mostración de su armazón, de su estructura primigenia, que no es otra que imágenes fijas sin las que no existiría. Y precisamente, en este punto es donde emerge "lo fotográfico". Dentro del ámbito de "lo fotográfico" en la filmografía de Almodóvar nos centramos en dos modalidades: el congelado de imagen y la fotografía recreada.

\section{Congelado de imagen}

Una reflexión de Víctor Burgin sirve para comenzar a abordar la fórmula más conocida mediante la cual el cine se convierte en foto: "Equiparar movimiento con cine y quietud con fotografía equivale a confundir la representación con su soporte material, dado que la película puede mostrar un objeto inmóvil, aunque el propio rollo de película se mueva a 24 fotogramas por segundo" (BURGIN, 2004, p. 218). Nos referimos al congelado de la imagen, a ese momento en el que el cineasta decide detener el tiempo fílmico para fijar una imagen.

Bellour, de acuerdo con Burgin, además, reflexiona sobre los beneficios de cara al público: "En el filme detenido (o en el fotograma), la presencia de la foto resplandece [...] tiene un privilegio sobre todos los efectos gracias a los cuales el espectador de cine, ese espectador apurado, se vuelve también un espectador pensativo" (BELLOUR, 2009, p. 82). Un espectador que ahora dispone de tiempo para repensar y analizar imágenes como cuando Tina y su hermano Pablo Quintero salen del estreno de una película de este último, se aproximan y el disparo fotográfico congela su abrazo en $L a$ 
ley del deseo o cuando David en Carne trémula a modo de paparazzo acciona el disparador de su cámara compulsivamente a la par que se detiene el metraje. Estas interrupciones que congelan la imagen encuentran su justificación en el hecho de que el espectador pueda vislumbrar mejor la relación amorosa entre Víctor y Clara (Ángela Molina). En este sentido, Parejo considera que este mecanismo propicia un valor añadido a la significación por "ser el fotograma elegido y porque promueve una exploración sobre sí mismo en aras de descubrir aquello que no es posible visualizar en movimiento" (PAREJO, 2012, p. 76).

En Los abrazos rotos el instante seleccionado para ser detenido es el último beso en Lanzarote antes del accidente de Lena y Mateo, que por su granulosidad recuerda a la fotografía de la playa del Golfo. Un último beso que Mateo intenta atrapar con sus manos acariciando la pantalla, como el niño protagonista de la película de Bergman Persona lo hiciera en 1966. La peculiaridad de esta simbiosis entre la imagen cinematográfica detenida que deviene en congelado fotográfico y la de la imagen en movimiento (las manos) reside en la capacidad de simular estar cerca y a la vez lejos. Y esto se debe según Melendo (2012, p. 54) a que una imagen refrenda "la pura materialidad de una película que insiste en la componente constitutiva del filme, y que ofrece al espectador distintos mecanismos de reflexión en relación a la imagen, incluida la televisiva o electrónica".

Precisamente, y vinculado a la imagen televisiva, Almodóvar ya había presentado con anterioridad una escena similar en Matador. Se trata del momento en el que el torero Diego revisa la corrida en la que sufrió una cogida. Tras rebobinar, detiene la imagen en el 
contraplano de la plaza que se congela para mostrar al público. La cámara cinematográfica se aproxima hasta que reconocemos a su antiguo amor, María (Assumpta Serna), que recobra el movimiento en el instante que percibimos el grito de esta cuando ve como el toro le zarandea. Diego vuelve a detener la imagen y la besa.

\section{La imagen fija recreada}

En el caso inverso al congelado se sitúan aquellas imágenes fílmicas que parten de una fotografía. Anteriormente se expuso como a partir de una fotografía tomada por Almodóvar el cineasta reconstruye ese momento en el rodaje de Los abrazos rotos. En este sentido, el cineasta manifiesta que "Antes que los vídeos o los súper-8 del pasado, me sugieren mucho más las fotografías. Provocan un gran misterio. El tiempo favorece el contenido expresivo de las fotos, va dándole significados" (BELINCHÓN, 2018). Además, refiriéndose a la foto de Ramón Masats titulada Seminario de Madrid (1960), representada en La mala educación, señala que "Ese tipo de fotografía española siempre me ha apasionado" (BELINCHÓN, 2018). En esta producción también se localiza un homenaje a la fotografía Students, 1883 de Thomas Eakins, que posteriormente sería reproducida en uno de sus cuadros más conocidos y polémicos, Swinning Hole, 1884. Aunque la reconstrucción no es literal, ambos recuerdan a la escena en la que el padre Manolo acompaña a sus mejores alumnos en una excursión por el campo que incluye un chapoteo junto a unas rocas, del mismo modo que Eakins capta cuando sus alumnos se disponen a bañarse. 
Otra recreación, aunque en esta ocasión parcial, es la efectuada por Ricky al final de ¡Átame! Este camina por un pueblo abandonado (el de su niñez) con una fotografía antigua en la mano en la que se ve a una pareja con un niño en la puerta de su casa, la número 11. La función principal de la imagen es localizar esa vivienda. En la cinta la fachada fotográfica da paso por asociación mediante un barrido en vertical a la original, parcialmente destruida. Los recuerdos de Ricky parecen desvanecerse y se acomoda abatido sobre la piedra que también se sentó para la foto años antes.

\section{Conclusiones}

En este texto partíamos de tres objetivos concretos: el primero determinar los mecanismos mediante los que Almodóvar inserta fotografías en sus producciones, el segundo, establecer las tipologías más recurrentes en su filmografía y finalmente, precisar las funcionalidades de esas imágenes. En relación al primero se ha constatado que se sintetizan en dos fórmulas: la presencia de la fotografía como objeto real y lo que se ha denominado "lo fotográfico". Entendemos por las primeras, aquellas imágenes fijas cuyo soporte proviene estrictamente de la fotografía, independientemente de la variedad de dispositivos en los que, como se ha expuesto, pudieran colocarse. La segunda forma con la que Almodóvar cuenta para introducir imágenes fijas es recurriendo directamente al aparato cinematográfico, ya bien cuando lo detiene o cuando a partir de una fotografía pone en marcha su maquinaria para recrearlo.

En cuanto a las tipologías que más se reiteran es preciso 
relacionarlas con las fórmulas anteriores. En el último caso, lo fotográfico deviene en el congelado de imagen y la fotografía recreada. Como se evidencia, son dos planteamientos opuestos, que consisten, como diría Roland Barthes, en posar la imagen o a partir de una imagen fija hacerla avanzar. Por su parte, los objetos reales son recurrentes en la ambientación de los decorados y como elemento narrativo.

Respecto al último de los objetivos, las funcionalidades que se detectan se corresponden con la tipología empleada. Es decir, en el caso de la ambientación de decorados distinguimos que el papel que desempeñan las fotografías se vincula a homenajear a intérpretes reconocidos (habitualmente actrices de Hollywood), relacionar las fotografías con la temática de la película (fotos de gais, travestis...), adornar estancias con instantáneas de carácter familiar que servirán de punto de arranque de escenas y mostrar fotografías que para Almodóvar cuentan con un valor sentimental.

Si nos referimos a la fotografía como elemento narrativo, las funcionalidades oscilan entre la imagen identificativa, la metafórica y la que ejerce como detonante/inspiración de la narración. Las identificativas sirven para mostrar el pasado (los personajes interactúan con ellas y establecen un nexo entre pasado y presente), efectuar descubrimientos (acerca de la identidad de un personaje o sobre sus relaciones de parentesco o afectivas) y presentar a un personaje (habitualmente al principio donde confluyen la imagen y una descripción de la persona retratada). Las metafóricas aluden a rupturas de relaciones amorosas mediante instantáneas arrojadas o fragmentadas o a la búsqueda del restablecimiento del pasado a través de su recomposición. Por otra parte, las que actúan como detonante/ 
inspiración de la narración sirven de base para esta y muestran el acto fotográfico.

Finalmente, los congelados de imagen constatan que promueven la reflexión en dos sentidos: sobre el porqué del fotograma seleccionado y la posibilidad de su análisis. Por otro lado, la imagen recreada cumple con el papel de rendir un homenaje a un fotógrafo o el encuentro con el pasado a través de su reinterpretación.

Tras el estudio de las diversas fórmulas, tipologías y funcionalidades estamos en condiciones de ratificar la premisa de partida. Es decir que la presencia de la fotografía en el cine de Almodóvar se integra como un elemento narrativo más, a la par que forma parte de la ambientación también como un objeto real. Sin embargo, el ámbito de lo fotográfico (cuando el cine se transforma en foto o viceversa), aunque presente, es raramente mostrado. A partir de aquí, también se puede afirmar que existe prevalencia de la fotografía como objeto real sobre la que muestra el acto fotográfico. Además, si retomamos la noción de campo de referencia se constata que Almodóvar prioriza el momento de la recepción, esto es la relación de la copia con el sujeto-espectador. En este caso, entendiendo por este no solo el público, sino los personajes de la película que interactúan con las fotografías.

\section{Referencias}

ALLISON, Mark. El uso de la cámara desde Pepi, Luci, Boom... hasta Hable con ella. En: ZURIÁN, Francisco; VÁZQUEZ, Carmen (ed.). Almodóvar: el cine como pasión. Actas del Congreso internacional Pedro Almodóvar. Cuenca: Ediciones Universidad 
Castilla- La Mancha, 2005. p. 147-154.

ARROYO, María Dolores. Pepi, Luci, Bom...Transgresión sexual y cultura popular. ICONO 14, Madrid, España, v. 9, n. 3, p. 256274, 2011. DOI: https://doi.org/10.7195/ri14.v9i3.44.

BAZIN, André. ¿Qué es el cine? Madrid: Ediciones Rialp, 1990.

BELINCHÓN, Gregorio. Usé la fotografía como un ansiolítico. El País, Madrid, 7 jul. 2018. Disponible en: http://bit.ly/2LGRzvp. Acceso en: 30 oct. 2020.

BELLOUR, Raymond. Entre imágenes: foto: cine: vídeo. Buenos Aires: Ediciones Colihue, 2009.

BROULLÓN, Manuel. Intertextualidad e hiperdiscursividad en Los abrazos rotos (Pedro Almodóvar, 2009). Frame: Revista de Cine de la Biblioteca de la Facultad de Comunicación, n. 7, p. 124-145, 2011.

BURGIN, Víctor. Ensayos. Barcelona: Editorial Gustavo Gili, 2004.

DUBOIS, Philippe. De la imagen, del otro o de la influencia del cine en la fotografía creativa contemporánea. Revista Exit, Madrid, Spain, n. 3, p. 130-145, 2000.

DUBOIS, Philippe. El acto fotográfico. Barcelona: Paidós, 2002.

DUBOIS, Philippe. La photo tremblée et le cinéma suspendu. La Recherche Photographique, Paris, n. 3, p. 19-27, 1987.

DUBOIS, Philippe. Fotografía \& Cine. México: Ediciones VE, 2013.

FONT, Domènec. Fotografía y cine: hibridaciones: la extraña pare- 
ja. Revista Exit, Madrid, Spain, n. 3, p. 16-31, 2000.

GUERRA, Antonio. Producción audiovisual: partidas presupuestarias unificadas. Madrid: M-Soft, 1994.

LEDO, Margarita. Cine de fotógrafos. Barcelona: Gustavo Gili, 2005.

MELENDO Ana. La naturaleza metafílmica de Los abrazos rotos. Fotocinema: Revista Científica de Cine y Fotografía, Málaga, España, n. 5, p. 41-61, 2012. DOI: doi.org/10.24310/Fotocinema.2012.v0i5.5895

MOHOLY-NAGY, László. Pintura, fotografía, cine. Barcelona: Editorial Gustavo Gili, 2005.

OUBIÑA, David. Una juguetería filosófica: cine, cronofotografía $\mathrm{y}$ arte digital. Buenos Aires: Ediciones Manantial, 2009.

PANTOJA, Antonio. La fotografía como pretexto para la creación cinematográfica. En: DE LAS HERAS, Beatriz (ed.). El fotógrafo como testigo de la historia. Madrid: Ediciones Ocho y medio, 2014. p. 69-101.

PAREJO, Nekane. La expresión de lo fotográfico en el cine. En: ACLE, Daniel; HERRERO, Francisco Javier (ed.). Expresión, análisis y crítica de los discursos audiovisuales: cine. La Laguna, Tenerife: Sociedad Latina de Comunicación Social, 2012. p. 65-77.

PERALES, Francisco. Pedro Almodóvar: heredero del cine clásico. ZER - Revista de Estudios de Comunicación, Bizkaia, Spain, v. 13, n. 24, p. 281-301, 2008.

POYATO, Pedro. El cine en el cine: Los abrazos rotos (Pedro Almodóvar, 2009). Fotocinema: Revista Científica de Cine y Fotografía, Málaga, España, n. 5, p. 7-23, 2012 b. 
POYATO, Pedro. Identidad visual y forma narrativa en el drama cinematográfico de Almodóvar. Madrid: Editorial Síntesis, 2015.

POYATO, Pedro. Referencias intertextuales de Carne Trémula (Almodóvar, 1997). ZER - Revista de Estudios de Comunicación, Bizkaia, Spain, v. 17, n. 32, p. 121-139, 2012 a.

REA, Peter W.; IRVING David K. Producción y dirección de cortometrajes. Madrid: Instituto Oficial de Radio y Televisión, 1998.

SÁNCHEZ NORIEGA, José Luis. Universo almodóvar: estética de la pasión en un cineasta posmoderno. Madrid: Alianza Editorial, 2017.

TRANCHE, Rafael. De la foto al fotograma. Madrid: Ocho y medio, 2006. 